\title{
Increase in mean platelet volume in patients with chronic renal failure treated with erythropoietin
}

\author{
P C Sharpe, Z R Desai, T C M Morris
}

\begin{abstract}
Aims-To assess whether r-HuEPO (recombinant human erythropoietin) has any effect on thrombopoiesis in patients with chronic renal failure.

Methods-This was a retrospective study of 78 patients with chronic renal failure undergoing either haemodialysis $(n=57)$ or intraperitoneal dialysis $(n=21)$. All patients had a full blood count (in EDTA) measured before starting r-HuEIPO and at monthly intervals thereafter up to six months. Variables studied were haematocrit, platelet count, mean platelet volume (MPV) and platelet distribution width (PDW). Other groups of control patients were also studiedpatients with chronic renal failure receiving dialysis but not r-HuEPO $(n=40)$ and a group of patients with normal renal function who were receiving aspirin $(n=30)$.

Results-There was a significant increase in mean haematocrit $(p<0.01)$ and in mean platelet volume $(p<0.001)$ over the six month period, but no change in either total platelet count or platelet distribution width in the patients with chronic renal failure receiving r-HuEPO. In contrast, both the control groups showed no significant change in MPV. Conclusions-The results suggest that r-HuEPO affects thrombopoiesis and may be part of a group of humoral factors contributing to megakaryocyte development and maturation. Larger platelets are more reactive and may contribute to the increased risk of thrombosis associated with r-HuEPO.
\end{abstract}

$(\mathcal{F}$ Clin Pathol 1994;47:159-161)

Chronic renal failure is associated with bleeding problems, indicated by decreased platelet aggregation and prolonged bleeding times. ${ }^{12}$ Patients receiving r-HuEPO (recombinant human erythropoietin) treatment show improved haemostasis and increased platelet aggregation,,$^{3-6}$ and one of the well known side effects of r-HuEPO is an increased risk of thrombosis. ${ }^{7}$ Recent evidence has shown that larger platelets are more reactive per unit volume than smaller platelets and are more likely to aggregate, leading to thrombosis. ${ }^{8-10}$ Large platelets seem to be an independent risk factor for myocardial infarction, and platelet size is one predictor of recurrent myocardial infarction and death. ${ }^{10}$

It is now known that there are receptors for EPO on the megakaryocytes of rats and mice $^{1112}$ and that platelet size is determined at or before the megakaryocyte budding stage. ${ }^{13}$ It has also been shown that r-HuEPO acts as a humoral growth factor and promotes differentiation of murine megakaryocytes. ${ }^{14}$

\section{Methods}

This was a retrospective study of 78 patients (40 men and 38 women), whose ages ranged from 17 to 84 years (mean age 56 years) with chronic renal failure receiving $r-H u E P O$ (Eprex) under the care of the regional renal unit in Belfast City Hospital. Fifty seven of the patients were undergoing haemodialysis (on a twice to three times a week basis) and the other 21 were receiving intraperitoneal dialysis (IPD). All patients had normochromic, normocytic anaemia associated with renal failure; other causes of anaemia had been excluded by regular measurements of serum ferritin, vitamin $B_{12}$ and folate. Forty of the 78 patients were receiving regular supplemental iron-dextran injections.

The dose of r-HuEPO began at $50 \mathrm{IU} / \mathrm{kg}$ twice weekly (by subcutaneous injection), increasing to $75 \mathrm{IU} / \mathrm{kg}$ twice weekly after two to three months if there was an insufficient rise in haematocrit and haemoglobin. It is the policy of the renal unit to give aspirin to all patients starting $\mathrm{r}-\mathrm{HuEPO}$. Twelve out of the 78 patients did not receive aspirin during the six month period of study as they had been given r-HuEPO before the establishment of this policy.

All the patients had a full blood count (in EDTA) measured on a Coulter STKS (Coulter Electronics, Northwell Drive, Luton, Beds) at monthly intervals from baseline (before starting r-HuEPO) up to six months. As a result of organisational procedure both within the renal wards and the haematology laboratory, most of the samples would have been analysed within 4 hours of venepuncture, but we cannot exclude a few samples having been analysed at a later time. The variables studied were haematocrit, platelet count, mean platelet volume (MPV) and platelet distribution width (PDW).

Changes in these variables were compared with baseline values and statistically analysed using Student's paired $t$ test. A measure of the difference between the maximum value of a variable achieved over the six month period and baseline was calculated and used in the 


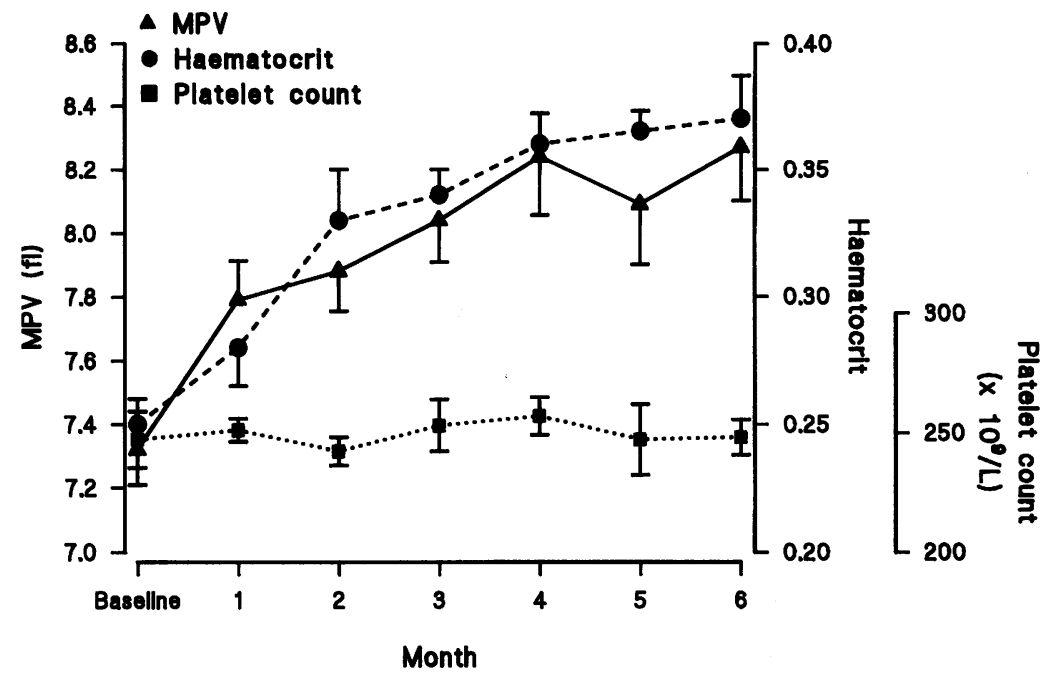

Figure 1 Mean (SEM) MPV, haematocrit, and platelet count $\left(\times 10^{\circ} / \mathrm{l}\right)$ compared with

analyses of the various subgroups (men/ women; age groups; haemodialysis/intraperitoneal dialysis, etc) using the unpaired $t$ test.

A group of 40 patients with chronic renal failure not receiving r-HuEPO but undergoing dialysis was also followed up from baseline (before starting dialysis) up to six months (22 men and 18 women, age range 24-78 years, mean 51.3 years; 29 receiving haemodialysis, 11 intraperitoneal dialysis). Unfortunately we were unable to obtain a full set of perfectly age and sex matched controls due to insufficient numbers.

A group of 30 patients who had had a myocardial infarction (post myocardial infarct) but normal renal function (16 men and 14 women) who were all given aspirin at diagnosis were also studied at baseline, three months, and six months (blood was analysed within 4 hours of venepuncture).

The control patients (those receiving dialysis but not $r-H u E P O$ and the post myocardial infarct group receiving aspirin) were analysed using the paired $t$ test.

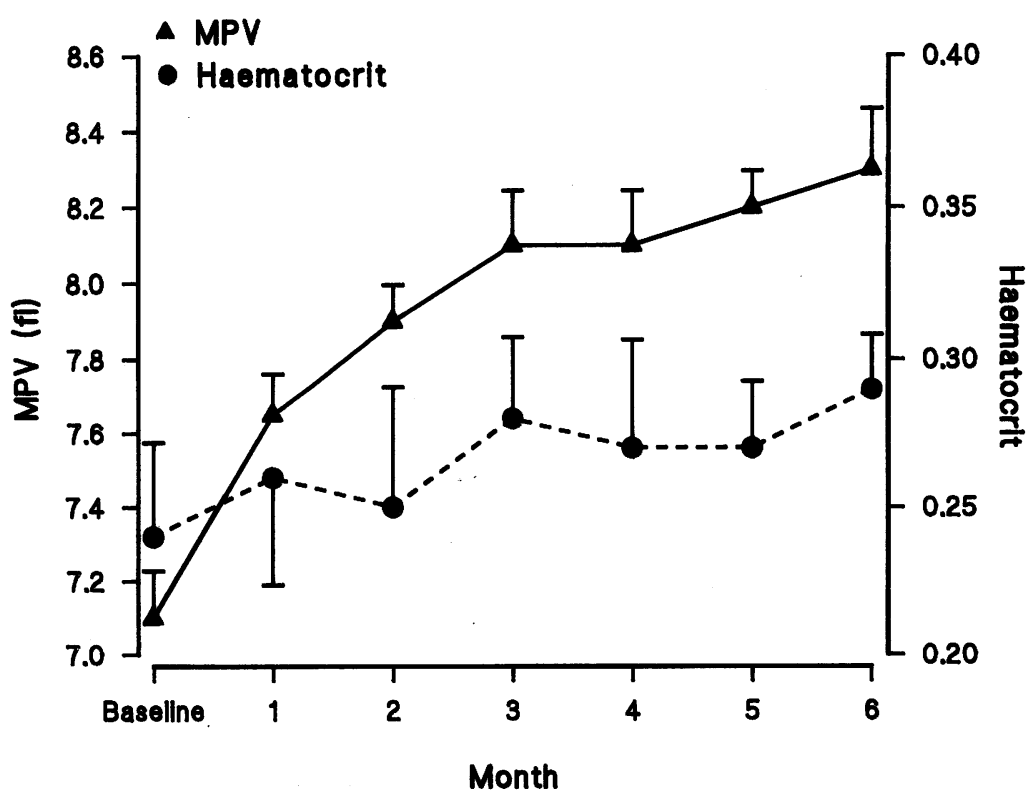

Figure 2 Mean MPV and haematocrit compared with month in 10 patients who displayed less than a 0.05 increase in haematocrit.
Demographic details of patients with thrombotic events

\begin{tabular}{clll}
\hline & $\begin{array}{l}\text { Haematocrit } \\
(\%)\end{array}$ & $\begin{array}{l}\text { Platelet } \\
\text { count 10\%ll }\end{array}$ & $M P V(f)$ \\
\hline $\begin{array}{c}\text { Female 50 } \\
\text { AV fistula } \\
\text { thrombosis }\end{array}$ & $35 \cdot 6(24 \cdot 3)$ & $273(248)$ & $9 \cdot 1(6 \cdot 9)$ \\
$\begin{array}{c}\text { Female 55 } \\
\text { Myocardial }\end{array}$ & $32(25 \cdot 6)$ & $261(260)$ & $8.9(7 \cdot 5)$ \\
$\begin{array}{c}\text { infarction } \\
\text { Female 51 } \\
\text { AV fistula } \\
\text { thrombosis }\end{array}$ & $31(21.9)$ & $255(301)$ & $8 \cdot 8(7 \cdot 2)$ \\
\hline
\end{tabular}

Pre-EPO baseline; other figure, results at time of thrombotic event.

\section{Results (fig 1)}

There was a significant increase in the mean haematocrit of the patients receiving r-HuEPO over the six month period when compared with baseline values $(p<0.01)$, rising from 0.24 (SEM 0.01 ) at baseline to $0.37(0.02)$ at month 6 . There was no significant difference in this increase when the following subgroups were compared: men and women; age groups $17-50$ and 51-84; haemodialysis and intraperitoneal dialysis; and those patients receiving iron-dextran and those not receiving iron-dextran injections. Ten of the total 78 patients had less than a 0.05 increase from baseline in haematocrit over the six month period. There was no significant change in total platelet count over the six month period or in platelet distribution width (PDW).

Mean platelet volume (MPV) of patients receiving $\mathrm{r}-\mathrm{HuEPO}$ showed a significant increase each month compared with baseline values $(p<0.001)$, rising from $7.322(0.112)$ to $8.279(0.169)$ at month 6 . The 10 patients with a less than 0.05 rise in haematocrit over the six month period had the same degree of increase in MPV as the others (fig 2). These 10 patients plus five others were receiving the higher. dose of r-HuEPO (75 units $/ \mathrm{kg}$ ) and this group had no statistically greater increase in MPV compared with the rest on the lower dose (50 units $/ \mathrm{kg}$ ). There were no significant differences in the increase of MPV between the various subgroups (men and women, age groups, etc) or between the 12 patients who did not receive aspirin during the six month period and the other 66 who did. Three of the 78 patients had thrombotic episodes during the six month period. The results of haematocrit, platelet count, and mean platelet volume are given in the table.

The 40 patients receiving dialysis but no erythropoietin (r-HuEPO) showed no significant change in mean platelet volume (MPV) throughout the six month period, neither did the 30 post-myocardial infarction patients receiving aspirin.

\section{Discussion}

We have shown a significant increase in mean platelet volume (MPV) $(p<0.001)$ in a group of patients with chronic renal failure treated with $\mathrm{r}-\mathrm{HuEPO}$. The dialysis process itself and medications such as aspirin and iron-dextran injections do not seem to affect the MPV. The increase in MPV does not 
seem to be dependent on a rise in haematocrit under the effect of r-HuEPO as shown by the group of patients with a small rise in haematocrit but with a similar increase in MPV as the others. MPV increased to the same extent under both the lower and higher doses of r-HuEPO, suggesting that there is not a linear dose dependent response.

Chronic renal failure is associated with impaired haemostasis manifest in decreased platelet aggregation and prolonged bleeding times. ${ }^{12}$ Because larger platelets are more reactive and have been reported to be associated with both cerebral ${ }^{15}$ and myocardial infarction ${ }^{1016}$ we suggest that the increase in MPV shown in this study may be one factor in the correction of the haemostatic defect of chronic renal failure and the increased risk of thrombosis which is now recognised as a side effect of r-HuEPO. Platelet volume is seen as a variable that relates to haemostatic function $^{17}$ and larger platelets are known to produce more thromboxane $\mathrm{A}_{2},{ }^{9}$ contain denser granules, and secrete more serotonin and $\beta$ thromboglobulin compared with those of smaller size, while larger platelets are known to aggregate preferentially in the presence of adenosine diphosphate. ${ }^{18}$

It used to be believed that larger platelets were younger platelets and that r-HuEPO had a simple thrombopoietin-like action ${ }^{61219} 20$ resulting in increased numbers of younger and therefore larger platelets. The process of platelet production is still not fully understood, but platelets seem to be produced by fragmentation of the megakaryocyte ${ }^{21}$; they do not seem to change in size as they age, and mean platelet volume (MPV) is determined at the time of megakaryocyte fragmentation into platelets. ${ }^{13}$

Platelet production and megakaryocyte regulation seem to occur at multiple cellular levels ${ }^{22}{ }^{23}$ and some cytokines are involved in the proliferative process, others with maturation. 22 Several haemopoietic growth factors-interleukin-3, interleukin-6, interleukin 11, LIF (leukaemia inhibitory factor), $\mathrm{KL}$ (C-Kit ligand) and EPO itself-stimulate maturation of megakaryocytes which subsequently show increased size, number, and ploidy, ${ }^{14}$ 24-29 but there have been no reports on the size of platelets produced. Recent work has shown the existence of receptors for EPO on the megakaryocytes of rats and mice $^{1112}$ and it is possible that these are also present in man.

Our findings suggest that $\mathrm{r}-\mathrm{HuEPO}$ acts as a cytokine via receptors on the megakaryocyte and that this action is manifest in the increase in MPV. If this is so, r-HuEPO does not seem to be acting as a simple "thrombopoietin"-like factor as we could show no increase in platelet count. In our study platelet count seems to be independent of platelet size, suggesting that r-HuEPO acts stochastically on megakaryocytes to produce larger platelets.
We thank the renal physicians and nursing staff of the Belfast City Hospital for allowing us to study these patients. Thanks also to Mrs Barbara Scott, Mr Derek Sterling, and Mr Cieran Ennis for their assistance with the manuscript.

1 Deykin D. Uraemic bleeding. Kidney Int 1983;24:698-705.

2 Livio M, Benigni A, Remuzzi G. Coagulation abnormalities in uraemia: Semin Nephrol 1985;5:82-90.

3 Moia $\mathrm{M}$, Vizzotto L, Cattaneo $\mathrm{M}$, et al. Improvement in the haemostatic defect of uraemia after treatment with recombinant human erythropoietin. Lancet 1987;ii: 1227-9.

4 Taylor JE, Henderson IS, Stewart WK, Belch JJF Erythropoietin and spontaneous platelet aggregation in haemodialysis patients. Lancet 1991;338:1361-2.

5 Gordge MP, Leaker B, Patel A, Oviasu E, Cameron JS, Neild GH. Recombinant human erythropoietin shortens the uraemic bleeding time without causing intravascular the uraemic bleeding time without causing intravasc

6 Akizawa T, Kingusa E, Kitoaka T, Koshikawa S. Effects of recombinant human erythropoietin and correction of anaemia on platelet function in haemodialysis patients. Nephron 1991;58:400-6.

7 Eschbach JW, Adamson JW. Correction of the anaemia of haemodialysis (HD) patients with recombinant human erythropoietin: results of a multicenter study. Blood 1987;70(Suppl 1):134a.

8 Jakubowski JA, Thompson CB, Vaillancourt R, Valeri C $\mathrm{R}$, Deykin $\mathrm{D}$. Arachidonic acid metabolism by platelets $\mathrm{R}$, Deykin D. Arachidonic acid metabolism
of differing size. Br f Haematol 1983;53:503.

9 Martin JF, Trowbridge EA, Salmon G, Plumb J. The biological significance of platelet volume. Its relationship to bleeding time, platelet thromboxane $\mathbf{B} 2$ production and megakaryocyte nuclear DNA concentration. Thromb Res 1983;32:443-60.

10 Martin JF, Bath PMW, Burr ML. Influence of platelet size on outcome after myocardial infarction. Lancet 1991;338:1409-11.

11 Fraser JK, Tan AS, Lin FR, Berridge MV. Expression of specific high-affinity binding sites for erythropoietin on rat and mouse megakaryocytes. Exp Haematol 1989; 17:10-6.

12 Berridge MV, Fraser JK, Carter JM, Lin FK. Effects of recombinant human erythropoietin on megakaryocytes and on platelet production in the rat. Blood 1988;72: 970-7.

13 Thompson CB, Love DG, Quinn PG, Valeri CR. Platelet size does not correlate with platelet age. Blood 1983;62: 487-94.

14 Ishibashi T, Koziol JA, Burstein SA. Human recombinant erythropoietin promotes differentiation of murine megakaryocytes in vitro. $\mathcal{F}$ Clin Invest 1987;79:286.

15 D'Erasmo E, Aliberti G, Celi FS, Romagnoli E, Vecci E, Mazzuoli GF. Platelet count, mean platelet volume and their relation to prognosis in cerebral infarction. $₹$ Intern their relation to progn

16 D'Erasmo E, Aliberti G, Celi FS, Vecc E, Mazzuoli GF. Platelet count and mean platelet volume following myocardial infarction. Medicina 1988;8:58-60.

17 Martin JF, Trowbridge A. Platelet heterogeneity. In: Biology and pathology. London: Springer-Verlag, 1990.

18 Haver VM, Gear ARL. Functional fractionation of platelets. $₹$ Lab Clin Med 1981;97:187.

19 Carter JM, Lin FK. Effects of recombinant human erythropoietin on megakaryocytes and a platelet production in the rat. Blood 1988;72:970-7.

20 Van Geet C, Hauglustaine D, Verresen L, Vanrusselt $M$ Vermylen J. Haemostatic effects of recombinant human erythropoietin in chronic haemodialysis patients. human erythropoietin in chronic haem

21 Martin JF, Slater DN, Trowbridge EA. Evidence that platelets are produced in the pulmonary circulation by a physical process. Prog Clin Biol Res 1986;215:405-16.

22 Williams N, Eger RR, Jackson HM, Nelson DJ. Two factor requirement for murine megakaryocyte colony formation. F Cell Physiol 1982;110:101-4.

23 Williams N, Jackson H, Walker T, Oon SH. Multiple levels of regulation of megakaryocytopoiesis. Blood Cells 1989;151:123-33.

24 Ishibashi T, Kimura H, Uchida T, Kariyone S, Friese $P$, Burstein SK. Human interleukin 6 is a direct promoter
of maturation of megakaryocytes in vitro. Proc Natl Acad of maturation of megakary

25 Burstein SA. Interleukin 3 promotes maturation of murine megakaryocytes in vitro. Blood Cells 1986;67:469-84

26 Ishibashi T, Burstein SA. Interleukin 3 promotes the differentiation of isolated megakaryocytes. Blood 1986; 67:1512-4.

27 Teramura M, Kobayashi S, Hoshino S, Oshimi K, Mizoguchi $H$. Interleukin-11 enhances human megakaryocytopoiesis in vitro. Blood 1992;79:327-31.

28 Burstein SA, Henthorn J, Mei R, Williams DE. Mast cell growth factor (MGF) promotes human and murine growth factor (MGF) promotes human and murine
megakaryocytic (MK) differentiation in vitro. Blood megakaryocytic

29 Burstein SA, Meir J, Friese P, Turner K. Recombinant human leukaemia inhibitory factors (LIF) and interleukin-11 (IL-11) promote murine and human megakaryocytopoiesis in vitro. Blood 1990;76:450a. 